Gut, 1985, 26, 704-709

\title{
Topical methotrexate alters solute and water transport in the rat jejunum in vivo and rabbit ileum in vitro
}

\author{
C R PINKERTON, I W BOOTH, AND P J MILLA
}

\begin{abstract}
From the Institute of Child Health, London, and The Hospital for Sick Children, Great Ormond Street, London
\end{abstract}

SUMmARY The topical effect of methotrexate (MTX) on small intestinal hexose and ion transport has been studied using an in vivo steady state jejunal perfusion technique in the rat, and short circuited rabbit terminal ileum in Ussing chambers in vitro. In rat jejunum, perfusion with MTX $(1 \mu \mathrm{mol} / \mathrm{l})$ caused significant reductions in water, sodium, and glucose absorption within 110 minutes of exposure. Fructose absorption was, however, unimpaired. The same concentration of MTX, when added to the mucosal side of distal rabbit ileum caused significant increases in transmucosal potential difference, short circuit current and the unidirectional flux of chloride from serosa to mucosa. In the presence of a subphysiological magnesium concentration $(0 \cdot 3$ $\mathrm{mmol} / \mathrm{l})$, MTX resulted in the abolition of net sodium absorption and the conversion of net chloride absorption to secretion. We conclude that MTX has a topical effect on small intestinal transport which is independent of its effect on crypt cell kinetics.

The early use of folic acid antagonists in cancer chemotherapy was associated with severe intestinal toxicity and extensive ulceration of small and large intestine occurred as a result of depressed crypt cell regeneration. ${ }^{1}$ In experimental animal, high dose or prolonged continuous methotrexate almost invariably results in hypoplastic villous atrophy, which causes malabsorption of a wide range of nutrients and drugs. ${ }^{2}$ In clinical practice, low dose methotrexate may also be associated with enterotoxicity and children with acute leukaemia receiving maintenance low dose MTX have impaired d-xylose absorption. ${ }^{3}{ }^{4}$ Similar observations have been made in the rat where an eight day course of low dose aminopterin (a close analogue of methotrexate) resulted in hexose malabsorption but no morphological change. ${ }^{5}$ Although severe enterotoxicity on low dose methotrexate is unusual, protracted diarrhoea has been reported ${ }^{6}$ and it has been postulated that the drug may be responsible for poor weight gain in some patients ${ }^{7}$ and possibly the malabsorption of other drugs. ${ }^{8}$

The present study was undertaken to determine whether enteral methotrexate in low doses, unlikely to cause changes in villous architecture, is associated

Address for correspondence: Department of Haematology and Oncology, Hospital for Sick Children, Great Ormond Street. London WCIN 3JH.

Received for publication 21 August 1984 with disturbances in intestinal transport which might contribute to diarrhoea. Effects on water and hexose transport were investigated using a steadystate perfusion technique in rat jejunum in vivo and effects on ion transport studied using short circuited rabbit distal ileum in vitro.

There is good evidence that hypomagnesaemia is a complication of diarrhoeal disorders, particularly those associated with an impaired intake of oral fluids and nutrients. ${ }^{9-11}$ Such circumstances may occur during cytotoxic therapy and the need for magnesium replacement may not always be fully appreciated as plasma $\mathrm{Mg}^{2+}$ concentrations are a poor indicator of total $\mathrm{Mg}^{2+}$ status. Furthermore, subphysiological concentrations of $\mathrm{Mg}^{2+}$ in vitro enhance the secretory response to $\mathrm{Mg}^{2+} .{ }^{12}$ The effects of MTX on ion transport were therefore determined under conditions of both physiological and subphysiological $\mathrm{Mg}^{2+}$ concentrations in vitro.

\section{Methods}

RAT STEADY STATE JEJUNAL PERFUSION IN VIVO Perfusions

Male Wistar rats weighing $250-300 \mathrm{~g}$ were fasted overnight but allowed water ad libitum. Anaesthesia was induced and maintained using intraperitoneal pentobarbitone $(6 \mathrm{mg} / \mathrm{kg}$ followed by $0.3 \mathrm{mg}$ doses 
as required). Rectal temperature was maintained at $37^{\circ} \mathrm{C}$ using overhead electric lamps. The abdomen was opened by a midline incision and a length of jejunum extending $15-20 \mathrm{~cm}$ distally from the duodenojejunal junction was isolated. This was cannulated at both ends and the luminal contents gently flushed out using a $0.9 \mathrm{NaCl}$ solution at $37^{\circ} \mathrm{C}$. The jejunal loop was then returned to the abdomen. Warmed perfusion fluid was infused continuously at a rate of $0.2 \mathrm{ml} / \mathrm{min}$ (Harvard 975 syringe pump). After an initial equilibration period of 50 minutes, five consecutive 20 minute collections of the effluent from the distal cannula were obtained. One group of animals was perfused with a basic solution which contained (mmol/l): $\mathrm{NaCl} 145 ; \mathrm{KCl} 4 ; \mathrm{NaHCO}_{3} 25$; glucose 2; and polyethylene glycol (PEG 4000) $3 \mathrm{~g} / \mathrm{l}$ labelled with $20 \mu \mathrm{Ci}{ }^{14} \mathrm{C}$ PEG (Amersham International Ltd.) as a non-absorbable marker. $\mathrm{pH}$ was adjusted to 7.0 by gassing with $\mathrm{CO}_{2}$; osmolarity of the solution was $290 \mathrm{mosmol} / \mathrm{l}$. Further groups were perfused with the basic solution to which one of the following was added: MTX $1 \mu \mathrm{mol} / \mathrm{l}$ (MTX Parenteral Solution, Lederle); folic acid $1 \mu \mathrm{mol} / \mathrm{l}$; fructose $20 \mathrm{mmol} / \mathrm{l} \pm \mathrm{MTX}$. Each animal was perfused with one solution only. At the end of each experiment the perfused loop was dissected, stripped of mesentery, opened along its mesenteric border, gently blotted dry and weighed. Each loop was then transferred into neutral buffered formalin solution and subsequently prepared for histological examination by light microscopy.

\section{Analytical methods}

The following were measured in duplicate in the initial perfusate and effluent solutions: sodium by flame photometry (Corning EEL); glucose by a hexokinase - G6PD method; fructose by initial conversion to G6PD by hexokinase and phosphoglucose isomerase, followed by glucose assay. Two hundred microlitre aliquots of solution were added to $10 \mathrm{ml}$ scintillation fluid (RIA Luma) and counted for ${ }^{14} \mathrm{C}$ in a liquid scintillation counter to determine PEG concentrations. For each perfusion period the PEG recovery was estimated and beyond the initial equilibration period the mean value for each experiment always exceeded $90 \%$.

\section{Calculations}

Net rates of water and solute absorption were calculated using standard formulae ${ }^{13}$ and statistical comparisons made between groups using Student's $t$ test.

\section{RABBIT SHORT CIRCUITED TERMINAL ILEUM IN} VITRO

After an overnight fast, Dutch brown male rabbits weighing between 1.8 and $2.3 \mathrm{~kg}$ were killed by a blow on the head and the terminal ileum mounted in Perspex half-chambers as previously described. ${ }^{12}$ Each surface of the mucosa was bathed separately with $12 \mathrm{ml}$ oxygenated $\left(95 \% \quad \mathrm{O}_{2} / 5 \% \quad \mathrm{CO}_{2}\right)$ KrebsHensleit solution at $37^{\circ} \mathrm{C}$ and $\mathrm{pH} 7.0$ containing (mmol/l): $\mathrm{Na}, 143 ; \mathrm{K}, 5 \cdot 7 ; \mathrm{Ca}, 1 \cdot 9 ; \mathrm{Mg}, 1.1$ or 0.3 ; $\mathrm{Cl}, 125 ; \mathrm{HCO}_{3}, 25 ; \mathrm{H}_{2} \mathrm{PO}_{4}, 1 \cdot 2$. Transmucosal potential difference (PD), short-circuit current (SCC) and uni-directional ion fluxes using ${ }^{22} \mathrm{Na}$ and ${ }^{36} \mathrm{Cl}$ were measured as described by Field et al ${ }^{14}$ using the formula of Schultz and Zalusky. ${ }^{15}$

Fluxes of radio labelled sodium and chloride were measured on paired tissues taken from adjacent segments of distal ileum. Tissues were only paired if their electrical resistances differed by less than $25 \%$. Forty minutes after mounting, $2 \cdot 2 \mu \mathrm{Ci}$ of ${ }^{22} \mathrm{Na}$ and $2 \cdot 2 \mu \mathrm{Ci}$ of ${ }^{36} \mathrm{Cl}$ (Amersham International Ltd.) were added to the mucosal solution of one tissue and to the serosal side of the other. Twenty minutes after the addition of isotopes, during which the tissues were short circuited, a $2 \mathrm{ml}$ sample was removed from each unlabelled bathing solution and a $100 \mu \mathrm{l}$ sample removed from each labelled solution for isotopic counting. Samples removed from the unlabelled solution were replaced with an equal volume of unlabelled bathing solution. Duplicate samples were taken 30 minutes later in order to determine base line fluxes. (Period A).

Under open circuit conditions, methotrexate (MTX) was added to the mucosal bathing solution to give a final concentration of $1 \mu \mathrm{mol} / \mathrm{l}$. Forty minutes after the addition of MTX, the tissues were again short circuited and after a 20 minute equilibration period, fluxes were again measured from initial and final samples taken 30 minutes apart. (Period B).

Two series of experiments were performed: one in which MTX was added to tissue bathed in a solution containing a physiological concentration of $\mathrm{Mg}^{2+}$ in vitro $(1 \cdot 1 \mathrm{mmol} / \mathrm{l})$ and a second in which tissue was bathed in a subphysiological concentration of $\mathrm{Mg}^{2+}$ in vitro $(0.3 \mathrm{mmol} / \mathrm{l})$. All values are expressed as means \pm 1 SEM. Statistical comparisons of fluxes before and after MTX exposure were made using Students paired $t$ test.

\section{Results}

RAT JEJUNAL PERFUSION IN VIVO

\section{Effects of methotrexate on net glucose, sodium and water transport}

The inclusion of MTX $(1 \mu \mathrm{mol} / \mathrm{l})$ in the basic perfusate resulted in progressive decreases in the rates of net jejunal absorption of glucose, sodium 
and water when compared with control animals perfused with basic perfusate alone (Fig. 1). Significant decreases were seen in net glucose absorption within 50 minutes of starting the perfusion $(\mathrm{p}<0.02)$, sodium by 70 minutes $(\mathrm{p}<0.01)$ and water by 110 minutes $(p<0 \cdot 01)$. When the experiments were concluded after 150 minute perfusion, transport rates in the animals perfused with MTX were still falling.

Histological examination by light microscopy of jejunal mucosa from MTX perfused and control animals, showed no evidence of morphological abnormality.

Effects of folic acid (1 $\mu$ molll) on net glucose, sodium and water transport

To determine whether the impaired transport seen in animals perfused with MTX is likely to be caused by a direct blockade of the brush border membrane glucose carrier, further perfusions were carried out in which folic acid, an extremely close structural analogue of MTX, was added to the basic perfusate. This addition made no significant difference to the rate of glucose, sodium or water transport compared to controls.

\section{Effects of addition of fructose in the presence and} absence of methotrexate

In view of the inhibitory effects of MTX on jejunal transport when perfused with an actively transported hexose (glucose), its effects in the presence of an additional, passively transported hexose were investigated. Fructose, which is passively transported by a carrier mediated process ${ }^{16}$ was therefore added to the perfusate and a further group of animals studied. The addition of fructose $(20 \mathrm{mmol} / \mathrm{l})$ did not result in significant changes in the rate of sodium or water absorption when compared with rates in the presence of glucose alone (Figs. 1, and 2). When animals were perfused with a solution containing glucose, fructose and MTX the inhibitory effects of MTX on water and sodium were again apparent although occurring somewhat later. By contrast the absorption of fructose remained unimpaired throughout the experiment (Fig. 2).

\section{SHORT CIRCUITED RABBIT TERMINAL ILEUM IN VITRO}

Methotrexate added to mucosal solution containing $\mathrm{Mg}^{2+1} 1.1 \mathrm{mmol} / \mathrm{l}$ (Table)

Addition of MTX resulted in small but sustained increases in short-circuit current $(\mathrm{SCC})(\mathrm{p}<0.001)$ and potential difference (PD) $(\mathrm{p}<0.01)$ which began within 10-15 minutes of MTX addition and continued rising slowly for the duration of the experiment. A significant increase in the flux of chloride from serosa to mucosa occurred $\left(\mathrm{JCl}_{\mathrm{sm}}\right.$; $\mathrm{p}<0.05)$, sufficient to abolish net chloride absorption $\left(\mathrm{JCI}_{\text {net }}\right)$ although this latter change did not reach statistical significance. No significant
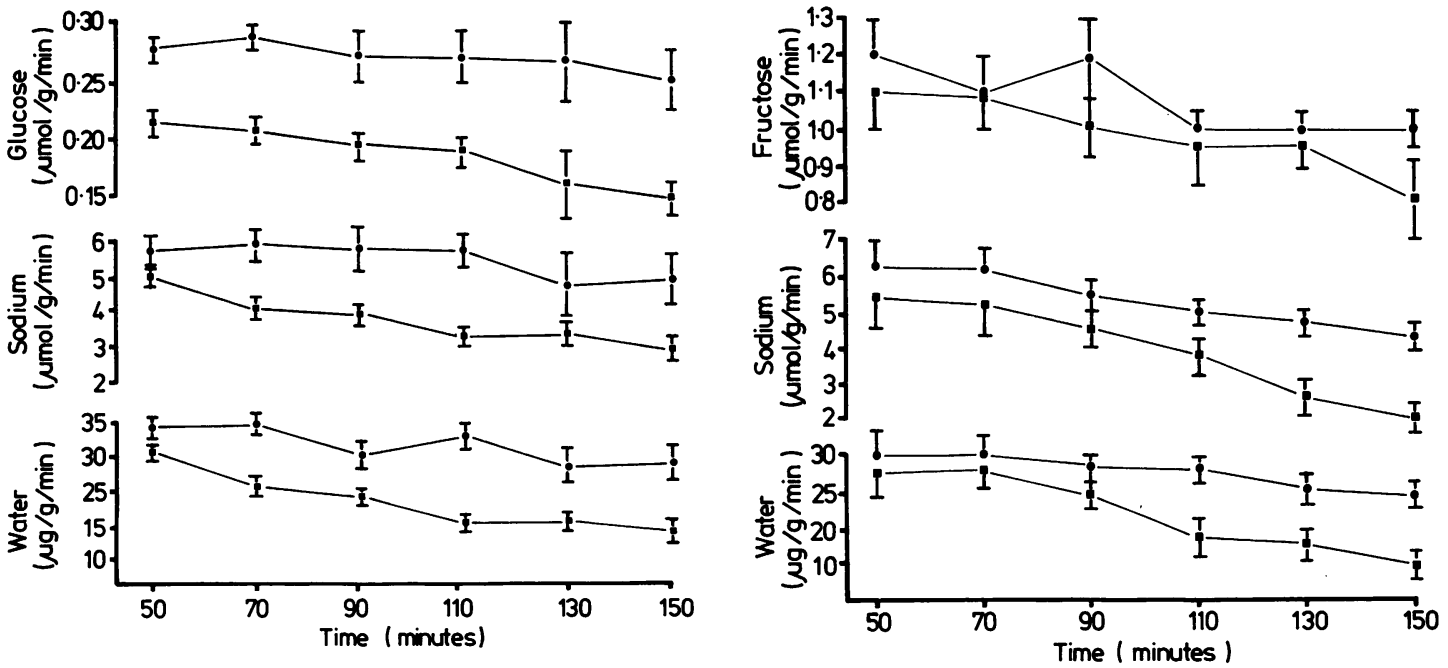

Fig. 1 Absorption of water, sodium and glucose from rat jejunum in the presence $(\mathbf{\square})$ and absence $(\mathbf{O})$ of methotrexate. (1 $\mu \mathrm{mol} / \mathrm{l}) \mathrm{n}=10$ in each group. Mean $\pm S E$.

Fig. 2 Absorption of water, sodium and fructose from rat jejunum in the presence $(\square)$ and absence $(\mathbf{O})$ of methotrexate $(1 \mathrm{\mu mol} / \mathrm{l}) \mathrm{n}=10$ in each group. Mean $\pm S E$ 
Table Effects of mucosal MTX $\left(10^{-6} \mathrm{~m}\right)$ on ileal ion transport. (MTX added to mucosal solution between periods $A \& B$ ).

\begin{tabular}{|c|c|c|c|c|c|c|c|c|c|c|}
\hline & \multicolumn{3}{|c|}{$\mathrm{Na}\left(\mu \mathrm{mol} / \mathrm{h} \mathrm{\textrm {cm } ^ { - 2 }}\right.$} & \multicolumn{3}{|c|}{$C l\left(\mu \mathrm{mol} / \mathrm{h} \mathrm{cm}^{-2}\right)$} & \multirow{2}{*}{$\begin{array}{l}\text { Scc } \\
(\mu \mathrm{mol} / \mathrm{h} \\
\left.\mathrm{cm}^{-2}\right)\end{array}$} & \multirow{2}{*}{$\begin{array}{l}\text { JRnet } \\
(\mu m o l / h \\
\left.\mathrm{cm}^{-2}\right)\end{array}$} & \multirow{2}{*}{$\begin{array}{l}P D \\
(m V)\end{array}$} & \multirow{2}{*}{$\begin{array}{l}R t \\
\left(\text { ohms cm }{ }^{-2}\right)\end{array}$} \\
\hline & Jms & Jsm & Jnet & Jms & $J s m$ & Jnet & & & & \\
\hline \multicolumn{11}{|c|}{$\mathrm{Mg}: 0.3 \mathrm{mmol} / \mathrm{l}$} \\
\hline Period A & $10 \cdot 16 \pm 0 \cdot 95$ & $9 \cdot 27 \pm 0.71$ & $+0.88 \pm 0.52$ & $8.43 \pm 0.69$ & $7 \cdot 88 \pm 0.36$ & $+0.55 \pm 0.84$ & $1.96 \pm 0 \cdot 18$ & $1.63 \pm 0.54$ & $2 \cdot 2 \pm 0 \cdot 2$ & $87 \pm 4$ \\
\hline $\begin{array}{r}\text { Period B } \\
n=9\end{array}$ & $9 \cdot 60 \pm 0 \cdot 58$ & $11 \cdot 25 \pm 1 \cdot 05$ & $-1.65 \pm 0.92^{*}$ & $8 \cdot 33 \pm 0 \cdot 56$ & $10 \cdot 73 \pm 0 \cdot 81$ & $-2 \cdot 40 \pm 0.80 \dagger$ & $2 \cdot 00 \pm 0 \cdot 19$ & $1 \cdot 26 \pm 0.75$ & $2.9 \pm 0.3$ & $86 \pm 4$ \\
\hline $\mathrm{Mg}: \stackrel{P}{1 \cdot 1 \mathrm{mn}}$ & NS & $<0.02$ & $<0.05$ & NS & $<0.002$ & $<0.002$ & NS & NS & $<0.01$ & NS \\
\hline Period A & $10 \cdot 76 \pm 1.09$ & $8.15 \pm 0.74$ & $+2.61 \pm 0.76$ & $8.93 \pm 0.60$ & $7.52 \pm 0.39$ & $1.41 \pm 0.81$ & $1.96 \pm 0 \cdot 18$ & $+0.77 \pm 0.56$ & $2 \cdot 2 \pm 0 \cdot 1$ & $66 \pm 3$ \\
\hline $\begin{array}{c}\text { Period B } \\
n=9\end{array}$ & $10 \cdot 34 \pm 1 \cdot 10$ & $8.81 \pm 0.98$ & $+1.53 \pm 1.04$ & $9 \cdot 08 \pm 0 \cdot 71$ & $9.73 \pm 0.97$ & $-0.66 \pm 0.98^{*}$ & $2 \cdot 48 \pm 0 \cdot 14$ & $+0.29 \pm 0.61$ & $2 \cdot 6 \pm 0 \cdot 1$ & $64 \pm 3$ \\
\hline $\mathrm{P}$ & NS & NS & NS & NS & $<0.05$ & NS & $<0.001$ & NS & $<0.01$ & NS \\
\hline
\end{tabular}

$\mathrm{Jms}=$ mucosa to serosa flux; Jsm =serosa to mucosa flux; Jnet=net flux; SCC=short circuit current; JRnet =residual ion flux; $\mathrm{Rt}=\mathrm{electrical}$ resistance; $\mathrm{PD}=$ transmucosal potential difference; $+=$ net absorption; $-=$ net secretion; $\mathrm{NS}=$ not significant $;{ }^{*}=\mathrm{NS}$ different from zero; $\dagger=$ significantly different from zero; values given as mean \pm 1 SEM.

changes occurred in sodium fluxes or in the residual ion flux $\left(J R_{\text {net }}\right)$.

\section{Methotrexate added to mucosal solution containing $\mathrm{Mg}^{2+}(0 \cdot 3 \mathrm{mmoll}$ ) $($ Table $)$}

The mucosal addition of MTX to ileum bathed in a solution containing a sub-physiological concentration of $\mathrm{Mg}^{2+}$, resulted in changes not only in chloride but also in sodium fluxes. $\mathrm{JCl}_{\mathrm{sm}}$ increased $(p<0.002)$, sufficient to convert net chloride absorption to net secretion $(p<0.002)$. Net sodium absorption was abolished $(\mathrm{p}<0.05)$ as a result of an increase in the flux of sodium from serosa to mucosa $(\mathrm{JNa} ; \mathrm{p}<0.02)$. Although the potential difference increased significantly $(p<0.01)$ there was no accompanying increase in short circuit current for reasons which are unclear.

In control experiments, in which MTX was not added to the mucosa before the second flux measurement period, there was no significant change in fluxes at either $\mathrm{Mg}^{2+}$ concentration between the periods $\mathrm{A}$ and $\mathrm{B}$. (data not shown). Basal fluxes, before exposure to MTX, were not statistically different at the two $\mathrm{Mg}^{2+}$ concentrations studied.

\section{Discussion}

This study shows that MTX has a potent topical effect on small intestinal transport, which is rapid in onset and occurs in the absence of morphological mucosal change. MTX binds dihydrofolate reductase (DHFR), preventing the conversion of folic acid to tetrahydrofolate and blocking DNA synthesis. One major effect of systemic methotrexate is therefore on the actively dividing crypt enterocyte where a high percentage of cells in the synthetic ( $S$ phase) of division and are thus susceptible to methotrexate toxicity. Within a few hours of drug administration, inhibition of mitosis is evident $^{1718}$ and where this is sustained an imbalance develops between the shedding of mature enterocytes and their replacement from the crypts. Prolonged exposure after high doses or continuous administration is associated with progressive villous hypoplasia and ultimately severe atrophy.

The changes in intestinal transport associated with local MTX cannot be explained on the basis of such effects on intestinal epithelial cell turnover and appear to result as a direct effect on the enterocyte. Dihydrofolate reductase is also an important coenzyme in a number of other one carbon transfer reactions and consequently the synthesis of RNA and protein in mature cells may also be influenced by MTX. ${ }^{19}$ Previous studies have suggested that the mature villous enterocyte is affected by this non-S phase action. Within four hours of a single high dose of aminopterin, given systemically, there was a marked reduction in mucosal oxygen consumption and glycolysis ${ }^{20}$ and patchy cytoplasmic vacuolation is seen in villous enterocytes within three hours of low dose MTX administration in both children with leukaemia and adults with psoriasis. ${ }^{17} 27$ The precise mechanism of this early systemic effect is unclear, but may be due to disruption of cellular enzyme systems as a result of the inhibition of protein synthesis.

In the rat jejunum in vivo, the progressive decreases in net sodium, water and glucose absorption associated with local exposure to MTX could not be reproduced by folic acid, a close structural analogue of MTX, suggesting that impaired absorption is not simply because of competition by MTX for glucose binding sites. Fructose was normally absorbed in the presence of MTX. This preservation of fructose absorption, 
which occurs passively by a carrier mediated process, but inhibition of active glucose absorption supports the notion that MTX does not act directly on brush border membrane transport. It seems more likely that it inhibits one or more of those intracellular events which follow and are necessary for continuing glucose absorption. ${ }^{22}$ Studies by Kaminskas $^{23}$ support this hypothesis. In an Erlich ascites tumour cell preparation it was shown that MTX rapidly inhibited glycolysis, depressed cellular ATP and impaired glucose uptake. The latter was restored by correction of ATP depletion. There was no evidence that MTX affected the saturation characteristics of glucose transport and the changes in uptake were observed before suppression of protein synthesis by MTX became apparent.

Although high dose systemic MTX leads to reduced activity of $\mathrm{Na}^{+} \mathrm{K}^{+}$ATPase in rat jejunal enterocytes within 48 hours $^{24}$ the role of this enzyme in the mediation of the currently reported changes is unknown.

In addition to effects on jejunal hexose transport topical MTX also induces early and marked changes in rabbit ileal electrolyte transport in vitro. These changes are exaggerated, both quantitatively and qualitatively, in the presence of sub-physiological concentrations of $\mathrm{Mg}$. A similar enhancement has been observed in the secretory response of ileum to high $\mathrm{Mg}$ concentrations in vitro. ${ }^{13}$ Although intestinal secretion has been previously described in association with radiation enteropathy, ${ }^{25}$ the changes in transport currently described occur in the absence of gross mucosal morphological changes. Taminiau et $a l^{24}$ have reported reduction in net sodium fluxes, in response to glucose, after systemic MTX, but did not examine the effects on chloride transport in their experiments. An early effect upon intracellular glycolysis has previously been reported ${ }^{23}$ but the relevance of this to our findings is unclear. Thus the mechanisms by which transport is influenced remain speculative and although these data show that functional disturbances occur they give few clues to the precise factors involved. Study of other cytotoxics which act at different sites on cellular metabolism would be of value to elucidate the mechanisms of topical toxicity. All previous studies of cytotoxic enteropathy have, however, considered only the functional derangement associated with gross villous damage.

What are the possible clinical implications of this local toxic effect? In addition to direct exposure from oral doses up to $10 \%$ of a single dose of MTX is recycled within the enterohepatic system irrespective of the route of administration, ${ }^{21}$ and this provides a mechanism by which the jejunal mucosa might be exposed for long periods to potentially toxic drug concentrations.

The precise concentration of MTX in the small gut after oral or parenteral doses is unclear. The only published data showed that in a single case 24 hours after a small dose $(5 \mathrm{mg})$ the jejunal concentrations were $8 \times 10^{-9} \mathrm{M}$ and $17 \times 10^{-9} \mathrm{M}$ after oral and intramuscular administration respectively. At five days the concentration was $62 \times 10^{-9} \mathrm{M}$ showing considerable enterohepatic recycling. ${ }^{6}$ It is likely that higher concentrations are found in the small gut during the early absorptive phase after an oral dose or within a few hours of a parenteral dose. With current intermediate dose $\left(500 \mathrm{mg} / \mathrm{m}^{2}\right)$ and high dose (up to $13 \mathrm{~g} / \mathrm{m}^{2}$ ) schedules these concentrations probably exceed $10^{-6} \mathrm{M}$. Moreover after oral doses the duration of exposure of the small gut to MTX is variable. A group of 'slow absorbers' has been defined in whom serum drug profiles indicate prolonged residence in the small gut. ${ }^{26}$ In the present study the concentration of $10^{-6} \mathrm{M}$ was chosen as this is generally accepted as the concentration at which the drug exerts a cytotoxic effect on the intestinal mucosa. ${ }^{21}$

Protracted diarrhoea might therefore occur where there is an unusually high amount of MTX excreted in the bile $e^{6}$ and topical toxicity could also explain the prolonged xylose malabsorption associated with intermittent MTX administration in children with leukaemia. Malabsorption is evident for up to three weeks after a single dose of MTX, at which time the jejunal mucosa would be expected to have recovered from any systemic effects. Furthermore jejunal morphometry at this time has been shown to be normal. ${ }^{27}$ In conclusion these data show that MTX alters small intestinal transport by a previously unrecognised local action which may have an important role in the pathogenesis of malabsorption and diarrhoea seen in some patients on cytotoxic therapy.

We are grateful to Mr B Godfrey and the staff of the animal house of the Institute of Child Health. CRP was in receipt of a research fellowship from the Royal Belfast Hospital for Sick Children and IB was funded by an Eden Fellowship from the Royal College of Physicians, London.

\section{References}

1 Taylor SG, Hass GM, Crumrine JL, Slaughter DP. Toxic reactions of 4 amino-pteroyl glutamic acid (aminopterin) in patients with far advanced neoplastic disease. Cancer 1950; 3: 493-503.

2 Jolly LE, Fletcher HP. The effect of repeated oral dosing of methotrexate on its intestinal absorption in the rat. Toxicol Appl Pharmacol 1977; 39: 23-32. 
3 Craft AW, Kay HEM, Lawson DN, McElwain TJ. Methotrexate induced malabsorption in children with acute lymphoblastic leukaemia. $\mathrm{Br}$ Med J 1977; 2: 1511-2.

4 Pinkerton CR, Glasgow JFT, Bridges JM, Welshman SG. Enterotoxic effect of methotrexate: does it influence the drugs absorption in children with acute lymphoblastic leukaemia? Br Med J 1981; 282: 1276-7.

5 Small MD, Cavanagh RL, Gottlieb L, Colon PL, Zamcheck $H$. The effect of aminopterin on the absorption of xylose from the rat small intestine. Am J Dig Dis 1959; 4: 700-5.

6 Baird GM, Dossetor JFB. Methotrexate enteropathy. Lancet 1981; 1: 164.

7 Lewis IJ, Mainwaring D, Martin J. Enteropathy complicating maintenance therapy in acute lymphoblastic leukaemia. Arch Dis Child 1982; 57: 663-7.

8 Pearson AJD, Craft AW, Pledger JV, Eastham EJ, Laker MF, Pearson GL. Small bowel function in acute lymphoblastic leukaemia. Arch Dis Child 1984; 59: 460-5.

9 Booth CC, Hanna S, Balouris H, McIntyre I. Incidence of hypomagnesaemia in intestinal malabsorption. $\mathrm{Br}$ Med J 1963; 2: 141-4.

10 Thoren L. Magnesium deficiency in gastrointestinal fluid loss. Acta Chir Scand 1963; suppl 306.

11 Harris I, Wilkinson AW. Magnesium depletion in children. Lancet 1971; 2: 735-6.

12 Booth IW, Milla PJ, Harris JT. The effects of Mg on ion transport in short circuited rabbit terminal ileum. Clin Sci 1984; 66: 465-71.

13 Sladen GE, Dawson AM. Interrelationship between the absorption of glucose, sodium and water by the normal human jejunum. Clin Sci 1969; 36: 119-32.

14 Field M, Fromm D, McColl I. Ion transport in rabbit ileal mucosa. I. Sodium and chloride fluxes and short circuit current. Am J Physiol 1971; 220: 1388-96.

15 Schultz SG, Zalusky R. Ion transport in isolated rabbit ileum. I. Short circuit and sodium fluxes. J Clin Physiol 1964; 47: 567-84.

16 Sigrist-Elson K, Hopfer U. A distinct D-fructose transport system in isolated brush border membrane. Biochim Biophys Acta 1974; 367: 247-54.

17 Trier JS. Morphological alterations induced by methotrexate in the mucosa of human proximal intestine. 1. Serial observations by light microscopy. Gastroenterology 1962; 42: 295-305.

18 Pinkerton CR, Cameron CHS, Sloan JM, Glasgow JFT, Guavava NJT. Jejunal crypt abnormalities associated with methotrexate therapy in children with acute lymphoblastic leukaemia. J Clin Pathol 1982; 35: 1272-7.

19 Goldman ID. Effects of methotrexate on cellular metabolism: some critical elements in the drug-cell interaction. Cancer Treat Rep 1977; 61: 549-58.

20 Vitale JJ, Zamcheck N, Digiorgio J, Hegsted DM. Effects of aminopterin administration on the respiration and morphology of the gastrointestinal mucosa of rats. J Lab Clin Med 1954; 43: 583-94.

21 Bleyer WA. The clinical pharmacology of methotrexate. Cancer 1978; 41: 36-51.

22 Milla PJ, Atherton Da, Leonard JV, Wolff OH. Disordered intestinal function in glycogen storage disease. J Inher Metab Dis 1978; 1: 155-7.

23 Kaminskas E. Inhibition of sugar uptake by methotrexate in cultured Ehrlich ascites carcinoma cells. Cancer Res 1979; 39: 90-5.

24 Taminiau JA, Gall DG, Hamilton JR. Response of the rat small intestine epithelium to methotrexate. Gut 1980; 21: 486-92.

25 Goodner CJ, Moore TE, Bowers JZ, Armstrong WD. Effects of acute whole body $X$ irradiation on the absorption and distribution of $\mathrm{Na}^{22}$ and $\mathrm{H}^{3} \mathrm{OH}$ from the gastrointestinal tract of the fasted rat. Am J Physiol 1955; 183: 475-84.

26 Pinkerton CR, Welshman SG, Dempsey SI, Bridges JM. Absorption of methotrexate under standardised conditions in children with acute lymphoblastic leukaemia. Br J Cancer 1980; 42: 613-8.

27 Guavava NJJ, Pinkerton CR, Glasgow JFT, Sloan JM, Bridges JM. Small bowel enterocyte abnormalities caused by methotrexate therapy in acute lymphoblastic leukaemia of childhood. J Clin Pathol 1981; 34: 790-5. 